\title{
DOES TEAM-BASED LEARNING DEVELOP ESSENTIAL GENERIC SKILLS IN PHARMACY STUDENTS?
}

\author{
M. J. Eksteen \\ Department of Pharmacy Practice \\ North-West University \\ Potchefstroom, South Africa \\ e-mail: mariet.eksteen@gmail.com
}

\section{ABSTRACT}

In order to deliver graduates with the necessary qualities, skills and understanding to be employable, universities should do more than only teach disciplinary content. Team-Based Learning (TBL) is a small-group-based, active learning teaching strategy which supports the development of essential skills while mastering course content.

In this study, a questionnaire was used to collect biographical data. It consisted of 20 quantitative questions focusing on essential generic skills developed during the implementation of TBL in a fourth-year pharmacy course. Participation was voluntary and ethical approval was received from the faculty's ethics committee.

The results pointed out that pharmacy students developed essential generic skills such as teamwork, problem-solving, interpersonal skills, time management, communication and adaptability when TBL was used as teaching strategy. TBL provides an effective learning environment for diverse groups, which makes it a valuable teaching strategy in South African higher education settings.

Keywords: Team-based learning, pharmacy education, higher education, South Africa, skills development, employability skills, graduate attributes

\section{INTRODUCTION}

Higher education institutions are under severe pressure to produce employable graduates (Bridgstock 2009, 31; Glover, Law and Youngman 2002, 293). Graduate attributes, according to Bowden et al. (cited by Barrie 2004, 263; Bridgstock 2009, 32), are the qualities, skills and understanding students should develop during their time at an institution and which shape the contribution these students make as professionals in their careers and communities. However, it is not enough only to refer to graduateness as an indication of the level of knowledge, skills and understanding. A student needs to be employable. Employability is the process where students who have completed a degree are assimilated into employment (Glover, Law and Youngman 2002, 293). The debate on appropriate teaching and learning to prepare students to be employable is not new. Abraham Flexner $(1910,53)$ concluded more than a hundred years 
ago in the well-known Flexner report that passive lectures for medical students are ineffective. This report highlights many of the challenges that still face medical education today (Janssen et al. 2008, 63). Therefore, the nature of teaching and learning in higher education should address these challenges to ensure that students graduate with the needed skills for employment. Universities should do more than only teach disciplinary content (Green, Hammer and Star 2009, 18).

The South African Qualifications Authority (SAQA) issued level descriptors for the South African National Qualifications Framework (NQF) in 2012 (SAQA 2012, 1). The purpose of this framework is to ensure coherence in learning achievement in the allocation of qualifications (SAQA 2012, 3). The framework identifies 10 levels of qualifications with higher education training at levels 5 to 10 to ensure comparability of qualifications nationally and internationally. Undergraduate degrees are level 5 (first year) to 7 (third year), a professional or honors degree on level 8, a masters' degree on level 9 and a doctoral degree on level 10. In each of these level descriptors, a set of 10 categories is used to describe applied competencies (SAQA 2012, 3). These competencies for the NQF level 8, which is appropriate for a fourth-year pharmacy student in South Africa, are as follows:

- "Scope of knowledge - have an understanding of how to apply knowledge in particular contexts;

- Knowledge literacy - demonstrate the ability to interrogate multiple sources of knowledge in an area of specialisation;

- Method and procedure - apply appropriate standards to unfamiliar problems;

- Problem solving - demonstrate the ability to use a range of skills to address complex problems;

- $\quad$ Ethics and professional practice - address ethical issues based on critical reflection;

- Accessing, processing and managing information - the ability to critically review information gathered and synthesise data to develop creative responses;

- Producing and communicating of information - present and communicate academic, professional or occupational ideas to a range of audiences;

- Context and systems - able to operate effectively in a system;

- Management of learning - apply learning strategies to effectively address professional and ongoing learning needs; and

- Accountability - ability to take full responsibility for work, decision-making and use of resources, and full accountability for the decisions and actions of others where appropriate" (SAQA 2012, 10-11).

The NQF identified seven critical cross-field outcomes which are those generic outcomes that inform all teaching and learning. It should be incorporated in qualifications on the appropriate level on the SAQA level descriptors of the NQF (n.d., 1). Some of the critical outcomes adopted by SAQA are: 
- Identifying problems and solving them using responsible decision making and critical thinking;

- Effectively working with others in a team;

- $\quad$ Self-management, including one's activities; and

- $\quad$ Communicating effectively using different skills in oral or written presentations.

In terms of pharmacy education, the World Health Organization (WHO 1997, 3) published a guideline document for a seven-star pharmacist. According to this document, a pharmacist has seven roles as part of its practice: caregiver, decision-maker, communicator, manager, life-long learner, teacher and leader. In South Africa, the South African Pharmacy Council (SAPC) is the statutory body of the pharmacy profession. It adopted an eight-star pharmacist as part of the Good Pharmacy Education Standards (RSA 2014, 78), including the role of a researcher to the WHO's list. For every pharmacy curriculum implemented, the SAPC develop curriculum goals. The current curriculum, which was implemented in 2013, requires universities to deliver a pharmacist who can solve problems, apply knowledge and integrate knowledge from different fields of pharmacy.

TBL was first developed by Larry Michaelsen for his course in management (Parmelee 2008, 5). Over time, this active learning teaching strategy was included more and more in health professions education due to changing health care needs requiring professionals to have better teamwork skills (Parmelee 2008, 5). TBL is a small-group-based teaching strategy where students work in teams of between five and seven members. Passive, lecturer-based presentations of theory are moved out of scheduled classes to allow active student participation and engagement in application exercises. The primary learning objective of TBL is to provide students with the opportunity to practice problem solving using course concepts (Michaelsen and Sweet 2008, 10). It does not only challenge students intellectually but also provides the opportunity to develop interpersonal and teamwork skills (Parmelee 2008, 6) as students are working together in teams to solve problems they might face in future. It allows for transformation in the way health professions education is conducted, supporting the values and competencies that prepare a student for a future as a professional (Parmelee 2008, 7). TBL can address several professional competencies such as communication, interpersonal skills, teamwork, giving and receiving peer feedback, knowledge acquisition and application of knowledge in case problems (Parmelee 2008, 7). Studies conducted in Iran and the United States concluded that TBL allows students to learn new skills such as teamwork and 
communication (Amini et al. 2011, 8; Elmore, Skelley and Woolley 2014, 491).

This research article reports on a part of a larger research project which aims to develop guidelines for TBL in an undergraduate pharmacy curriculum. The objective of this article is to determine whether TBL allows pharmacy students to develop essential generic skills as required for pharmacists on NQF level 8. This study is unique as it is the first reporting on TBL implementation in a South African undergraduate pharmacy curriculum as an active teaching strategy which promotes the development of skills together with deeper learning. The findings of this study not only indicate whether TBL did promote the development of essential generic skills, but also point out where it is lacking and where adjustments can be made to improve the impact of TBL in skills development and over all pharmacy pedagogy at a higher education level.

\section{RESEARCH METHODOLOGY}

\section{Target and sample populations}

TBL was implemented in a fourth-year pharmacy practice module at a South African university. The target population $(\mathrm{N}=200)$ consisted of all registered students for this module during the 2016 academic year. All students in the target population were invited to participate in the research. However, not all students present in class on the day that the data were collected participated or gave informed consent that their data may be used in the research, resulting in a sample population of $183(91.5 \%)$ students who handed in completed questionnaires.

\section{Data collection tool and pre-testing}

For this study, a quantitative questionnaire was developed using current published literature on TBL. The questionnaire collected biographical data such as age, gender and ethnicity, as well as 20 quantitative questions focusing on generic skills development. The 20 Likert-type questions were answered using a 4 -scale rating $(1=$ strongly disagree, $2=$ disagree, $3=$ agree, $4=$ strongly agree $)$ as recommended by Berk $(2014,67)$ for measuring teaching effectiveness. Participants were asked to indicate with a cross which option best describes their opinion for each of the 20 questions. Students could only select one option per question and were instructed to complete all the questions.

This newly-developed questionnaire was tested through an exploratory investigation to detect errors in content and/or clarity before it was utilised in the main investigation (Delport and Roestenburg 2011, 195). Cognitive interviews were conducted with first and second year postgraduate students, respectively one or two years older than the study population in most 
cases, to see whether these students understood all the questions in general, understood all the words or phrases used in the questions, could provide the relevant answers and had any additional advice or suggestions on the questions' format (Wills 2005, 35). To test content validity, experts in the field of health professions education and pharmacy were asked to each complete and review the questionnaire and give feedback on the clarity and distinctness of the questions, the time needed to complete the questionnaire, any biasness created by questions, and general suggestions and/or recommendations. After this feedback was incorporated into the questionnaire, it was sent to a statistician for a face validity evaluation.

\section{Data collection and ethical considerations}

Participants were informed upfront that the data would be collected during a scheduled class period for this specific pharmacy practice module. Due to the fact that data were collected anonymously, there was only that one opportunity to participate in the research, as it would not be possible to validate if a student who ask to participate in the research at a later stage did not already completed a questionnaire.

Students received an information leaflet prior to the class to provide them with sufficient time to think about and consider participation in this research study. The leaflet contained information regarding the purpose of the study, procedure of data collection, benefits and risks/discomforts, remuneration, access to data, funding, ethical approval and feedback on the findings. Students who agreed to participate gave written informed consent indicating their willingness to participate. No remuneration was offered to any participants and there was no cost involved to participate. However, as an incentive ten coffee vouchers from a local coffee shop to the value of R50 were handed out via a lucky draw from the informed consent forms. Participation in the research was entirely voluntary and students were free to decline to participate. Although students were free to withdraw from the study at any point, even if they did initially agree to participate, it had to be done before submitting the completed questionnaire as there was no way of tracing the anonymous questionnaire back to a student.

The research project was approved by two separate South African university's ethics committees prior to commencement of the research. The questionnaire, information leaflet, informed consent form and data collection procedures were reviewed. All research was conducted according to the South African Ethics in Health Research (RSA DoH 2015) guidelines and principles of the International Declaration of Helsinki.

\section{Data analysis}

Data from the completed questionnaires were captured manually in a Microsoft Excel 
spreadsheet using the options 1 to 4 for each question to code the data. A random 10 per cent data entry spot check was done to confirm accuracy, and data error identification and rectification measures were applied as part of an iterative process. Missing data or unanswered questions could not be followed up as questionnaires were completed anonymously and were therefore left as is.

The IBM SPSS Statistics version 23, release 23.0.0 (SPSS 2016), was used to analyse the data.

\section{RESULTS AND DISCUSSION}

\section{Biographical data}

Question 1 of the questionnaire collected biographical data to compare the sample population with the target as well as the South African population. The sample population was representative of the target population in terms of gender, age and ethnicity as confirmed by the Pearsons chi-square test where the $p$-values $>0.05(0.67,0.91$ and 0.79 respectively) indicate no statistically significant association. The sample population consisted mostly out of female students (80.3\%), 22 years of age $(63.9 \%)$ and white $(90.7 \%)$, as indicated in Table 1.

Table 1: Biographical data of target and sample population

\begin{tabular}{|c|c|c|c|c|c|c|c|c|c|}
\hline \multirow{2}{*}{ Gender } & \multicolumn{2}{|c|}{$\begin{array}{c}\text { Target } \\
\text { population }\end{array}$} & \multicolumn{2}{|c|}{$\begin{array}{c}\text { Sample } \\
\text { population }\end{array}$} & \multirow{2}{*}{$\begin{array}{l}\text { Age in years } \\
\text { (as on } \\
31 / 12 / 2016 \text { ) }\end{array}$} & \multicolumn{2}{|c|}{$\begin{array}{c}\text { Target } \\
\text { population }\end{array}$} & \multicolumn{2}{|c|}{$\begin{array}{c}\text { Sample } \\
\text { population }\end{array}$} \\
\hline & $\mathbf{n}$ & $\%$ & $\mathbf{n}$ & $\%$ & & $\mathbf{n}$ & $\%$ & $\mathbf{n}$ & $\%$ \\
\hline Male & 41 & 20.5 & 34 & 18.6 & 21 & 1 & 0.5 & 0 & 0.0 \\
\hline Female & 159 & 79.5 & 147 & 80.3 & 22 & 129 & 64.5 & 117 & 63.9 \\
\hline Unknown & 0 & 0 & 2 & 1.1 & 23 & 45 & 22.5 & 44 & 24.0 \\
\hline \multirow{3}{*}{ Ethnic group } & \multirow{2}{*}{\multicolumn{2}{|c|}{$\begin{array}{c}\text { Target } \\
\text { population }\end{array}$}} & \multirow{2}{*}{\multicolumn{2}{|c|}{$\begin{array}{c}\text { Sample } \\
\text { population }\end{array}$}} & 24 & 16 & 8.0 & 16 & 8.7 \\
\hline & & & & & 25 & 6 & 3.0 & 3 & 1.6 \\
\hline & $\mathbf{n}$ & $\%$ & $\mathbf{n}$ & $\%$ & 26 & 1 & 0.5 & 0 & 0.0 \\
\hline White & 183 & 91.5 & 166 & 90.7 & 27 & 1 & 0.5 & 1 & 0.6 \\
\hline Other & 17 & 8.5 & 16 & 8.7 & 29 & 1 & 0.5 & 1 & 0.6 \\
\hline Unknown & 0 & 0 & 1 & 0.6 & Unknown & 0 & 0 & 1 & 0.6 \\
\hline
\end{tabular}

However, when this biographical data is compared with the South African population of pharmacy students, the majority of pharmacy students nationally are female (67\%) and African (54\%), Coloured (5\%) or Asian (16\%) (SAPC 2016a). A report by the Council of Higher Education (CHE 2013) on 2013 higher education data indicates that there was a 23 per cent increase in enrollment in higher education institutions between 2008 and 2013 where 34 per cent of all enrollment in 2013 were African students $(n=689,503)$. This report states that a 
proportional analysis of the ethnic groups was conducted and indicated that a larger percentage of Africans only enroll after the age of 35 years, whereas white and Indian students normally enroll before the age of 24 years (CHE 2013). The sample population used in this study were majority female students, which is in line with the national statistics for pharmacy students, and the average age of the white ethnic majority is also in line with the CHE report.

\section{Questionnaire data}

The descriptive statistics for all 20 questions are indicated in Table 2. For each question, the frequency for each option selected between strongly disagree and strongly agree was indicated followed by the mean and standard deviation for each question. The exploratory actor analysis (EFA) indicated that all 20 questions could be grouped together to form one factor, namely development of skills, due to the factor loadings ranging between 0.565 and 0.828 , which is higher than the guideline value of 0.3 (Field 2014, 681). The Cronbach's Alpha of 0.928 was higher than the guideline value of 0.8 and confirmed internal reliability (Pietersen and Maree 2007, 216). The discussion of the results was grouped according to the six skills targeted with TBL.

Table 2: Results of the TBL questionnaire

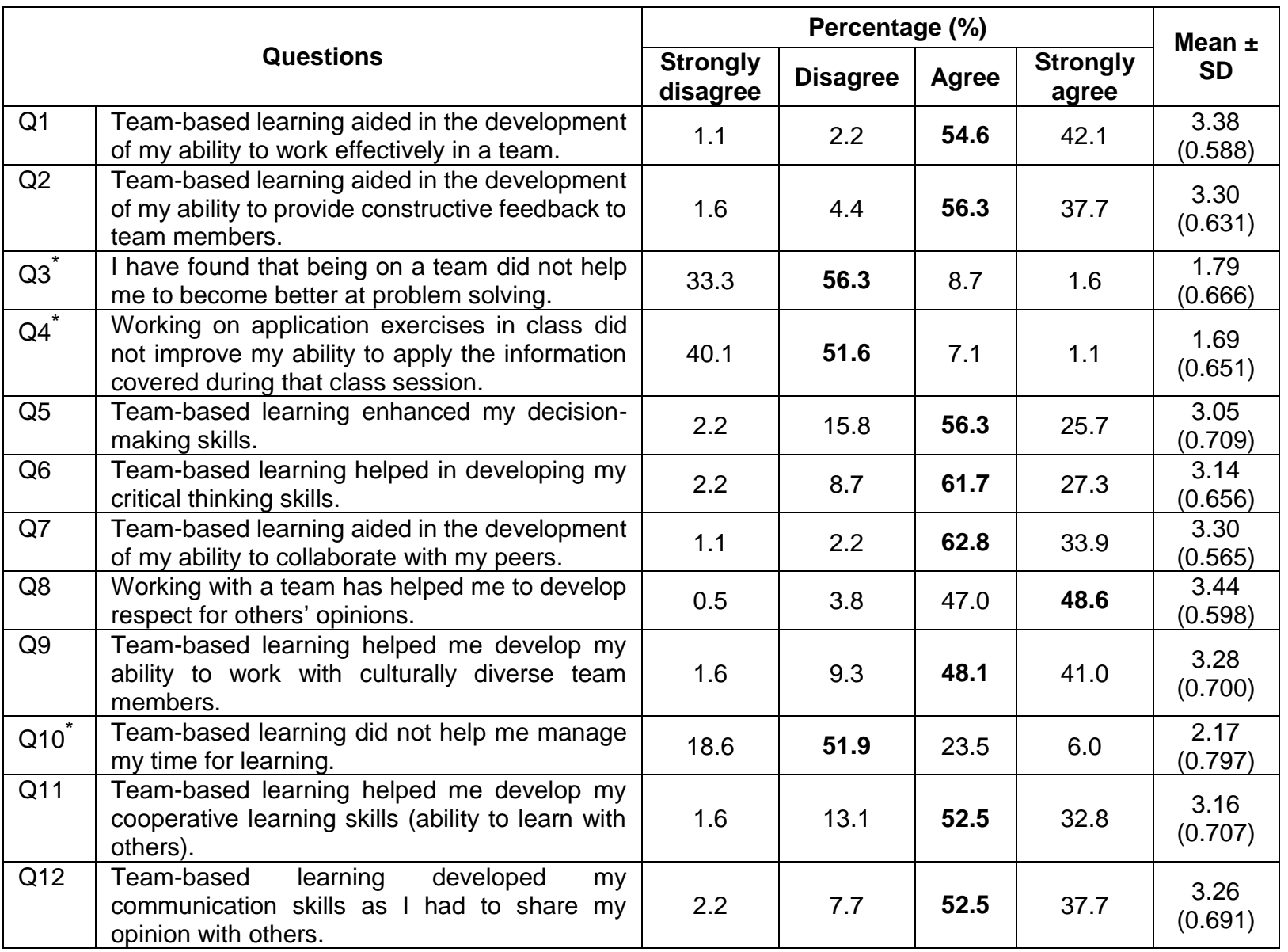




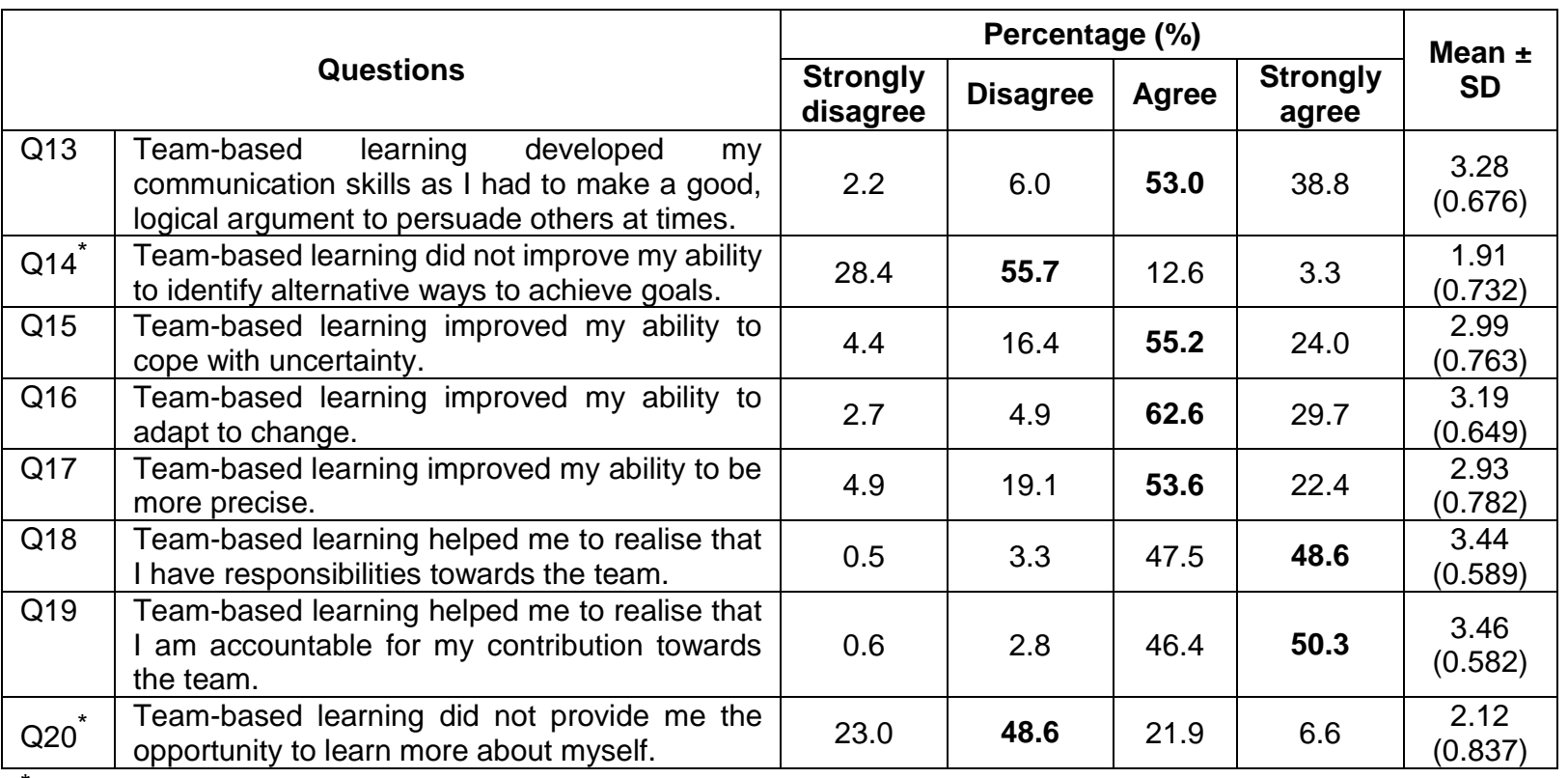

"Questions stated negatively.

\section{Team work skills}

Students felt that TBL aided in the development of their ability to work effectively in a team (Q1) and to provide constructive feedback to team members (Q2). Students also indicated that TBL helped them to develop their ability to work with culturally diverse team members (Q9). It helped students to realise that they have a responsibility (Q18) and are accountable for their contribution (Q19) towards the team.

Both the SAQA level descriptors and NQF critical cross-field outcomes refer to a graduate as being able to work effectively with others in a team (SAQA 2012, 11; NQF n.d., 1). In practice, pharmacists are part of the health care team working with doctors, medical specialists, pediatricians, nurses, etc. One of the competencies pharmacy students need to develop at university to be able to effectively contribute to the health care team is learning to work with others. Al-Meman, Al-Worafi and Saeed $(2014,60)$ concluded that in their study the implementation of TBL in a pharmacy practice module resulted in better team collaboration between students and contributed positively to the establishment of coherent teams. In another study by Elmore, Skelley and Woolley $(2014,492)$, they concluded that their adapted TBL strategy provided a valuable opportunity for student pharmacists to strengthen teamwork skills as it is also considered essential for a successful practicing pharmacist in Alabama, USA.

Although several courses in the BPharm curriculum require students to work in groups, creating the perception of adherence to above-mentioned national guidelines, there are fundamental differences between group work and team work (Robins, DeCenzo and Coulter $2015,311)$. When students work in groups, they usually demonstrate neutral or even negative synergy, prefer individual accountability, only share information needed to reach the goal and 
do not use their skills to complement the team (Robins, DeCenzo and Coulter 2015, 311). However, when working in a team, members demonstrate positive attitudes, accept mutual accountability in the team and perform collectively. Unfortunately, many students disregard the importance of working in a team rather than a group due to the lack of exposure to formal, structured team work. TBL can thus be used to ensure proper training and exposure to team work rather than group work. In South Africa, it is not only important to work with others in a team, but also with culturally diverse members. Part of the TBL strategy is to purposefully divide students in teams that are as heterogenic as possible (Michaelsen and Sweet 2008, 11). This learning environment provides students with the opportunity to interact with class mates they do not normally work with in a team, an essential contribution to the future work place.

\section{Problem-solving skills}

Students believed that being on a team helped them to become better at problem solving $\left(\mathrm{Q}^{*}\right)$. Students pointed out that working on application exercises in class improved their ability to apply information covered during that class session $\left(\mathrm{Q}^{*}\right)$. Students felt that TBL also enhanced their decision-making (Q5) and critical thinking (Q6) skills.

It is expected of pharmacists to solve problems regarding patient's health, medication and wellbeing on a daily basis. Problem solving varies between a patient asking for medication for a runny nose, to chronic medication being out of stock and deciding on a suitable replacement for a patient, or managing patient allergies and medication contra-indications. It is required of pharmacists to apply the theoretical knowledge studied, either at university or as part of continuing professions education, to solve problems like these. It requires the pharmacists to make accurate and safe decisions (Thamby and Subramani 2014,2) in the best interest of the patient and to evaluate each patient's profile critically to ensure optimal health. The incorporation of application exercises during TBL class time, and not just during tutorials where attendance is voluntary, force students to develop these skills.

\section{Interpersonal skills}

Students were of the opinion that TBL aided in the development of their ability to collaborate with their peers (Q7) and helped them develop cooperative learning skills (Q11) which is the ability to learn with others. While working in teams, students felt that it helped them to develop respect for other's opinions (Q8).

Pharmacists work with other health care professionals on a daily basis. They also learn from colleagues in the workplace, especially pharmacists who has been registered for a longer period. In South Africa, with its diverse cultural heritage, pharmacists will work with other 
pharmacy staff members from different ethnic groups (SAPC 2016a) who might have different views or opinions. It is in the best interest of the patient if these different role players have the ability to work together effectively to solve patients' health-related problems.

\section{Time management skills}

Students experienced TBL as helping them to manage their time for learning (Q10*). They also felt that TBL improved their ability to be more precise (Q17) and provided them with the opportunity to learn more about themselves $\left(\mathrm{Q}^{2} 0^{*}\right)$. Because TBL requires pre-class preparation from students, it needed additional time management from the student's side who has to plan for preparation time and study before each TBL class. It also requires students to be more precise as they write individual and team preparation tests before the lecturer explains any course concepts or ideas.

\section{Communication skills}

Because much discussion takes place during each TBL class, it is important to be able to communicate with team members. Students felt that TBL developed their communication skills as they had to share their opinions with others (Q12) and had to make a good, logical argument to persuade others at times (Q13).

Traditionally, the role of the pharmacist was more product-focused, whereas the current movement in the pharmacy professions is more patient-focused (Eksteen and Basson 2015, 43). Therefore, the current set of competence standards which forms the minimum requirement for an entry-level pharmacist to be registered as a pharmacist (SAPC 2016b, 42) mentions communication in six of the ten standards. Good communication skills are essential for pharmacists to ensure a provider-patient relationship and optimal health outcome (Boesen et al. $2009,1)$. Communication skills are not only important for a good relationship with patients but also with other health care professionals and community members (Thamby and Subramani $2014,2)$. Although the students in this study attended a semester course on communication for the pharmacist in their second year of study, TBL provided the opportunity to further practice and develop these skills in a different team-based setup.

\section{Adaptability skills}

According to the participants, TBL did improve their ability to identify alternative ways to achieve goals (Q14). They also felt that TBL improved their ability to cope with uncertainty (Q15) and being able to adapt to change (Q16).

Pharmacy is an ever-changing profession where medication that was freely available 
yesterday could be out of stock today, products that were on a medical aid formulary yesterday could be replaced by a cheaper generic today and a suitable treatment regime yesterday could not be suitable anymore today. Pharmacy students need to be exposed to these extremes to develop the skill of adaptability.

For this sample population, TBL was already a change as well as an uncertainty as they were used to traditional lectures. Secondly, they were required to prepare for class which they do not normally do. The distribution of participation marks was different, not being based on three or four assessments alone but on weekly individual and team readiness assurance tests. The goal for this course moved from memorizing content to the ability to apply it during applications exercises. Lastly, the content of assessments was not merely theoretical knowledge anymore but adheres to Bloom's taxonomy (NWU 2015, 4) in terms of cognitive levels for a course on NQF level 8. All of these aspects exposed the students to realities which called for adaptability.

\section{Correlations and independent t-tests}

Spearman's rho did not indicate a practically or statistically significant correlation between age and the development of skills factor $(\mathrm{r}=-0.001 ; p=0.990)$. Students' opinions regarding whether or not TBL aided with the development of skills were not influenced by their ages. Students in South African typically enter higher education at the age of 18 and will accordingly complete a four-year degree at the age of 22. However, due to reasons such as entering higher education at a later stage in live, transferring from another degree to pharmacy or failing one or more courses earlier in the curriculum which results in additional study years, there were several students in this study population older than 22 years.

The independent t-tests with Cohen's $d$-value also did not indicate practically or statistically significant differences between male and female students $(d=0.35)$ or between white students and students from other ethnicities $(d=0.23)$ such as African, Asian, Coloured, Indian and Korean. Therefore, TBL can be used to promote the development of essential skills in health professions education in mixed gender and multicultural classes, which is the norm in South African educational environments.

\section{RESEARCH FINDINGS, CONCLUSION AND IMPLICATION FOR HIGHER EDUCATION AND TRAINING}

This study set out to determine whether TBL allows pharmacy students to develop essential generic skills, as required for pharmacists on NQF level 8. For higher education in South Africa, there are several frameworks and legislation available to guide university staff in the training 
of undergraduate students in terms of learning achievements. Not only do they identify the categories used to describe applied competencies, they are also further developed for each level in the NQF. Furthermore, specific to pharmacy education, there are both national and international guidelines to ensure proper training of pharmacists to ensure a well-rounded graduate.

The study showed that TBL not only ensured deeper learning of theoretical content but also exposed students to a variety of activities and interactions which provided the opportunity to develop and practice certain important skills. Teamwork as a skill to collaborate with others was developed as all activities in the course were conducted in a team format which caused students to work together with other team members which they were not necessarily familiar with. All questions in the application exercises were case studies and based on contemporary problems students may face in future as health professionals, allowing students to develop problem-solving skills. Their collaboration in solving problems also developed their interpersonal skills as they had to work together to contribute to the team activities sufficiently and learn to collaborate with other team members respectfully. Since it was expected of students to come to class prepared to be tested in the first in-class activity, they had to develop time management skills to ensure enough time for preparation. Students had to discuss their opinions in a group and either be convinced by a fellow member or convince the team of their argument, which resulted in developing and practicing communication skills. Because TBL is different from traditional teaching methods, students had to learn to adapt to a new teaching strategy and its unfamiliar components. All of these skills are in line with required legislation in higher education (SAQA 2012, 10-11; NQF n.d., 1; RSA 2014, 78).

In light of the above findings, it is concerning how many courses still use traditional lecture methods, even with proof that these methods result in passive learners (Clark et al. 2008, 111), lower levels of knowledge retention (Deslauriers, Schelew and Wieman 2011, 864) and memorized course content most likely included in assessments (Marton and Saljo 1976, 117). A major disadvantage commonly expressed by university staff is the time needed to prepare a course according to the needed format. Another shortcoming could be that, regardless of the teaching strategy, the lecturer needs to be familiar with the strategy to ensure successful implementation. It is therefore recommended that the lecturer study current available literature and publications to familiarize themselves with the strategy and stay in frequent contact with an expert for assistance. It is important that university lectures include teaching strategies like TBL in training of health professionals.

This study shows that TBL fosters the development of essential generic skills that are included when referring to graduate attributes or employability skills. To develop graduates that 
have the necessary skills to effectively contribute to the health professions team, higher education needs to include active learning strategies in courses to ensure that university students' do benefit from lectures and not simply a theoretical lecture whose content can be studied alone as well. Students have a need for the development of interpersonal skills and the opportunity to work in heterogenic, interprofessional teams. Proper team work teaching strategies need to be implemented from the first year of study and not only in the final year. The implication for higher education classrooms in relation to the promotion of TBL as a teaching strategy is that graduates with not only theoretical knowledge but also essential generic skills, needed to be employable, will be delivered because these skills was developed during university training and no longer shifted to the employer to develop the graduate accordingly.

Although the implementation of TBL contributed to skills development in pharmacy students, one semester out of eight is not enough. Students are not adequately exposed to sufficient opportunities to re-enforce these skills on a constant basis and in different situations and scenarios, a direct result of higher education curriculums that are not adequately designed and planned to include the development of skills and to build on previously developed skills. This lack of exposure will limit the success of TBL in the long run, resulting in pharmacy students not fully equipped to function effectively as pharmacists or as part of the health care team.

Evidence like that from this study should be used to guide policies and legislation to ensure competent graduates in South Africa.

\section{RECOMMENDATIONS}

It is recommended that the findings of this study are used to address the lack of opportunities for skills development in the pharmacy curriculum. It is recommended that other pharmacy schools in South Africa also implement TBL as teaching strategy in their curriculums and to compare the impact of generic skills development in those contexts to this study. It would also be interesting to see whether other health curriculums experience the same level of skills development.

It could be of value to determine the impact of TBL on skills development as experienced by the employers of these final year students during their one-year compulsory internship following graduation.

\section{REFERENCES}

Al-Meman, A., Y. M. Al-Worafi and M. S. Saeed. 2014. Team-based learning as a new learning strategy in pharmacy college, Saudi Arabia: students' perceptions. Universal Journal of Pharmacy 3(3): 
$57-65$

Amini, M., S. Jafari, F. Lotfi, L. B. Afkan and Z. Karimian. 2011. The effect of team-based learning on study skill course of nutrition students of Shiraz University of medical sciences. Future of Medical Education Journal 1(1): 3-7.

Barrie, S. C. 2004. A research-based approach to generic graduate attributes policy. Higher Education Research \& Development 23(3): 261-275.

Berk, R. A. 2014. Top 10 flashpoints in student ratings and the valuation of teaching: What faculty and administrators must know to protect themselves in employment decisions. Virgenia: Stylus Publishing.

Boesen, K. P., R. N. Herrier, D. A. Apgar and R. M. Jackowski. 2009. Improvisational exercises to improve pharmacy students' professional communication skills. American Journal of Pharmaceutical Education 73(2): article 35.

Bridgstock, R. 2009. The graduate attributes we've overlooked: Enhancing graduate employability through career management skills. Higher Education Research \& Development 28(1): 31-44.

CHE see Council of Higher Education.

Clark, M. C., H. T. Nguyen, C. Bray and R. E. Levine. 2008. Team-based learning in an undergraduate nursing course. Journal of Nursing Education 47(3): 111-117.

Council of Higher Education. 2013. Higher education data. www.che.ac.za/focus_areas/ higher_education_data/2013/participation (Accessed 27 September 2016).

Delport, C. S. L. and W. J. H. Roestenburg. 2011. Quantitative data-collection methods: Questionnaires, checklists, structured observation and structured interview schedules. In Research at grass roots: For the social sciences and human service professions, ed. A. S. de Vos, H. Strydom, C. B. Fouché and C. S. L. Delport, 171-205. Pretoria: Van Schaik.

Deslauriers, L., E. Schelew and C. Wieman. 2011. Improved learning in a large-enrolment physics class. Science 332(6031): 862-864.

Eksteen, M. J. and M. J. Basson. 2015. Discovering the value of personality types in communication training for pharmacy students. African Journal of Health Professions Education 7(1): 43-46.

Elmore, L., J. Skelley and T. Woolley. 2014. Impact of adapted team-based learning methods on student self-assessment of professionalism, teamwork and skills in a self-care course. Currents in Pharmacy Teaching and Learning 6: 488-493.

Field, A. 2014. Discovering statistics using SPSS. ${ }^{\text {th }}$ Edition. London: Sage Publications.

Flexner, A. 1910. Medical education in the United States and Canada. Washington: Science and Health Publications, Inc.

Glover, D., S. Law and A. Youngman. 2002. Graduateness and employability: Student perceptions of the personal outcomes of university education. Research in Post-Compulsory Education 7(3): 293-306.

Green, W., S. Hammer and C. Star. 2009. Facing up to the challenge: Why is it so hard to develop graduate attributes? Higher Education Research \& Development 28(1): 17-29.

Janssen, H. F., N. P. Skeen, J. Bell and W. Bradshaw. 2008. Improving critical thinking skills in the medical professional with team-based learning. In Team-based learning for health professions education, ed. L. K. Michaelsen, D. X. Parmelee, K. K. McMahon and R. E. Levine, 61-73. Virginia: Stylus Publishing.

Marton, E. and R. Säljö. 1976. On qualitative differences in learning: Outcome as a function of learners' conception of task. The British Journal of Educational Psychology 46: 115-127.

Michaelsen, L. K. and M. Sweet. 2008. Fundamental principles and practices of team-based learning. In Team-based learning for health professions education, ed. L. K. Michaelsen, D. X. Parmelee, K. K. McMahon and R. E. Levine, 9-34. Virginia: Stylus Publishing.

National Qualifications Framework. n.d. What are the critical cross-field outcomes (CCFOs) and how do they relate to learning programmes? http://elearning.polytechnic.edu.na/elearn/pluginfile.php/ 
198808/mod_folder/content/0/Critical\%20Cross-Field\%20Outcomes\%20in\%20Teaching\%20 Law/SAQA\%20Critical\%20Cross\%20Field\%20Outcomes.pdf?forcedownload=1 (Accessed 28 September 2016).

North-West University. 2015. Blooms revised taxonomy. Potchefstroom: Academic Support Services.

NQF see National Qualifications Framework.

NWU see North-West University.

Parmelee, D. X. 2008. Team-based learning in health professions education. Why is it a good fit? In Team-based learning for health professions education, ed. L. K. Michaelsen, D. X. Parmelee, K. K. McMahon and R. E. Levine, 3-8. Virginia: Stylus Publishing.

Pietersen, J. and K. Maree. 2007. Standardisation of a questionnaire. In First steps in research, ed. K. Maree, 215-224. Pretoria: Van Schaik.

Republic of South Africa. 2014. Good pharmacy education standards in terms of section 34 of the Pharmacy Act, Act 53 of 1974. (Notice 153). Pretoria: Government Printers.

Republic of South Africa, Department of Health. 2015. Ethics in health research. Pretoria: Department of Health.

Robins, S. P., D. A. DeCenzo and M. Coulter 2015. Fundamentals of management. Boston: Pearson.

RSA see Republic of South Africa.

RSA DoH see Republic of South Africa, Department of Health.

SAPC see South African Pharmacy Council.

SAQA see South African Qualifications Authority.

South African Pharmacy Council. 2016a. Statistics for registered persons and organisations. http://www.sapc.za.org/B_StatsPerByGender.asp (Accessed 26 October 2016).

South African Pharmacy Council. 2016b. Intern and tutor manual for the pre-registration experience of pharmacist interns. Pretoria: South African Pharmacy Council.

South African Qualifications Authority. 2012. Level descriptors for the South African National Qualifications Framework. Pretoria: SAQA.

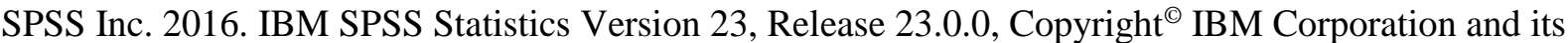
licensors. http://www-01.ibm.com/software/analytics/spss/ (Accessed 10 August 2016).

Thamby, S. A. and P. Subramani. 2014. Seven-star pharmacist concept by World Health Organization. Journal of Young Pharmacists 6(2): 1-3.

Wills, G. B. 2005. Cognitive interviewing: A tool for improving questionnaire design. Thousand Oaks: Sage Publications.

WHO see World Health Organization.

World Health Organization. 1997. The role of the pharmacist in the health care system. Vancouver: World Health Organization. 